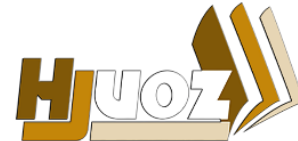

hjuoz.uoz.edu.krd p-ISSN: 2410-7557
كَّوارا زانستيّن مروّقايهتى يا زانكوّيا زاخوّ

مجلة العلوم الانسانية لجامعة زاخو

Humanities Journal of University of Zakho (HJUOZ)

Vol. 5, No. 2, pp. 314-322, June-2017

\title{
أثر اللغة العربية في الشعر الكردي \\ (الشاعر أحمدي خاني في مم و زين أنموذجاً)
}

عصام محمد سليمان

قسم اللغة العربية، كلية التربية عقره جامعة دهوك. (esamadke@yahoo.com)

https://doi.org/10.26436/2017.5.2.330

تاريخ القبول: 017/05 تاريخ النشر: 2017/06

تاريخ الاستلام: 2017/04

الخلاصة :

يتناول هذا البحث أثر اللغة العربية في الشعر الكردي عامة و شعر أحمدي خاني في ديوانه ( مم وزين ) خاصة ، لقد كانت اللغة العربية و لا تزال وسوف تبقى مصدراً خصباً ومعيناً ثراً لا ينضب بنصوصها المتنوعة المتميزة للشعراء عامة وشعراء الكرد الكلاسيكيين خاصة اللذين نهلوا منها سطور المجد والخلود . ويعد الشاعر أحمدي خاني أنموذجاً لهذا التأثير إذ يحتوي ديوانه ( مم وزين ) الكثير من الكلمات و الألفاظوالمعاني وأسماء الشخصيات العربية والإسلامية وهذا دليل على مدى أثر اللغة العربية في ثقافته وفكره ووجدانه وحبه للغة العربية . وينقسم البحث إلى مقدمة وتمهيد وثلاثة مباحث وخاتمة ذكرنا فيها أهم الاستنتاجات التي توصلنا إليها ـ أما المقدمة فتحثثنا فيها عن أهمية اللغة العربية وأثرها في الشعر الكردي ، وأما التمهيد فبينا فيه الكرد وأدبهم ثم تحدثنا عن الشاعر أحمدي خاني وسيرته وكتبه

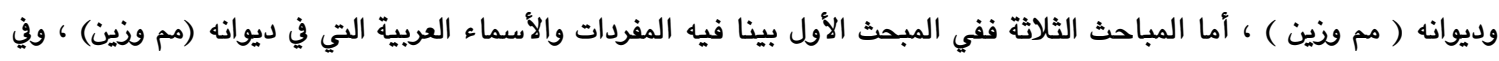

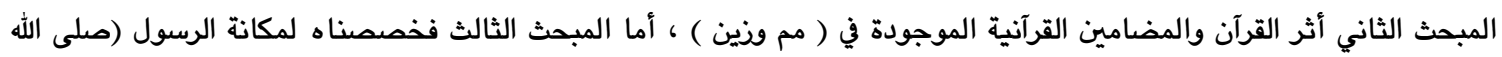

عليه وسلم ) والأحاديث النبوية الشريفة المتوفرة في ( مم وزين ) . الكلمات الدالة : أحمدي خاني، مم وزين، اللغة العربية، الكرد.

ساروا إلى طريق اللغة العربية ، معتمدين على تلاقح الثقافات وتلاقيها في تراث إنساني عام ، يجمع البشر جميعا تحت مظلة التأثر والتأثير، إذ لا يستطيع شعب ما العيش في هذا العالم دون التأثر والتأثير بغيره من الشعوب ويما أن اللغة العربية انتقلت إلى الكرد بطريق الفتح الإسلامي المجيد ، إذ دخل الكرد الإسلام عن طواعية واقتناع وحب .

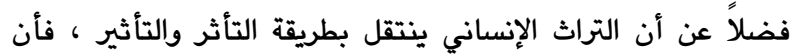

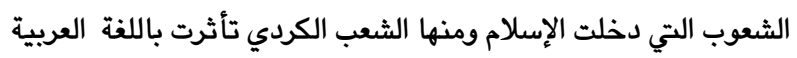

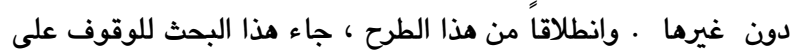

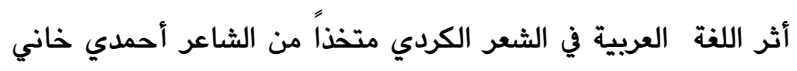
(1650- 1707 م) في ديوانه المتميز والشهير (مم وزين) أنموذجاً لهذا التأثير إذ يعد الشاعر من أبرز أعلام الشعر الكردي وأكثرهم إنتاجاً شعرياً وأحسنهم قولاً ومن الذين تأثروا بالعربية. لقد لاحظ الباحث أن الدراسات التي تناولت الشعر الكردي عامة وشعر أحمدي خاني خاصة مازالت مقصرةً في استجلاء أثر اللغة العربية في الشعر الكردي عامة ، وشعر أحمدي خاني خاصة ، وذلك لأسباب كثيرة ومتنوعة ، ريما منها أسباب أيديولوجية قومية منعت الكثير من الدارسين والباحثين من الكرد وغيرهم من دراسة هذا الجانب المهم في الدراسات الأدبية والنقدية .

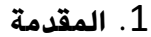

إن أول ما يلفت نظر الباحث في أدب اللغة الكردية، ما بينه وبين أحداث التاريخ وظروف البيئة من تجاوب عميق، وارتباط وثيق ، فعلى ضوء

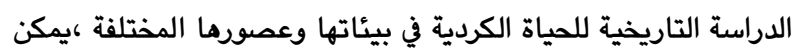
تفسير أكثر المفاهيم التي أداها هذا الأدب ، والاتجاهات التي اندفع إليها ، كما يمكن إدراك غير قليل من خصائصه الفنية. ومن مظاهر

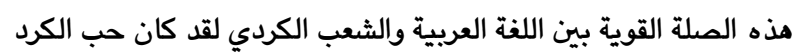
للغة العربية حقيقة لامراء فيها ، وكانت خدمتهم لها، وعنايتهم بدرسها

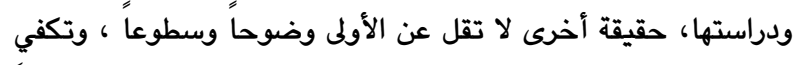

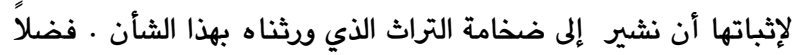

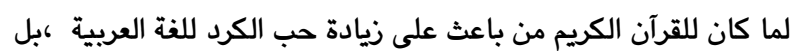
كان السبب في جعل أفئدتهم تهوي إلى اللغة العربية وتنشد معرفتها، باعن معرفة حذق وتخصص ليشاركوا إخوانهم ، العرب في فقه الدين ، وإدراك

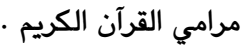
إن اللغة العربية كانت ولا تزال وسوف تبقى مصدراً خصباً، ومعيناً لا لا لعرئ ينضب بنصوصها المتنوعة المتميزة الثرية. لجأ الشعراء عامة وشعراء الكرد خاصة إليها لينهلوا من معينها الثر سطور المجد والخلود ، ولم يقتصر الشعراء الكرد على الانتهال من التراث الكردي فحسب ، بل 
المحلية مثل الكورانية واللورية ـ تكتب اللغة الكردية في العراق وايران

بالحروف العربية ، في حين تستعمل الحروف اللاتينية في تركيا . أما الأدب الكردي فبدأ مسيرته الجادة منذ القرن الحادي عشر الميلادي في (بايزيد وهكاري ويوتان) وياللهجة الكورمانجية ، ثم لم يلبث أن ازدمر باللهجات الأخرى ، وكان معظم مدونات هذا الأدب قصائد شعرية وباية ترتكز مضامينها على إحياء المثل العليا والتقاليد الكردية العريقة وإنها تشكل المواضيع الرئيسة لملاحم والحكايات والأساطير الشعبية والغزل • وأول ما يدهش له الباحث عند القيام بدراسة الأدب عند الكرد هو غزارة القصائد ولاسيما الشعبية ، وأن أكثر تلك القصائد تتحدث عن الحروب والمغامرات والحب ووصف الطبيعة . أما الحكايات والقصص فتدود حول مواضيع الفروسية والشجاعة والمروءة والنخوة والصفح والانتقام ، ومن أهم هذه القصائد الشهيرة عند الكرد قاطبة هي ملحمة الدفاع عن قلعة (دمدم) و ديوان (مم وزين) . أما الفن الشعري فواسع جدا عند الكرد أيضاً و واشتهر بينهم أدباء وشعراء ، كتبوا مؤلفات قيمة باللغة الكردية وكتب بعضهم بالعربية

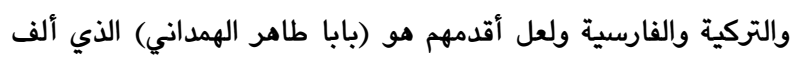

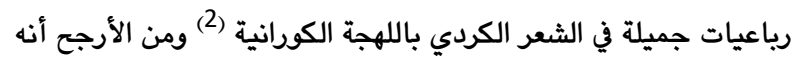

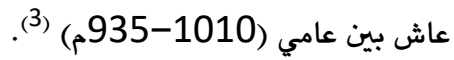
وإذ كان الدارسون والباحثون الكرد يضعون هذا الشاعر في بداية قافلة الشعراء الكرد فالسبب يبدو هو أنهم لا يملكون أدلة قاطعة أو سنداً

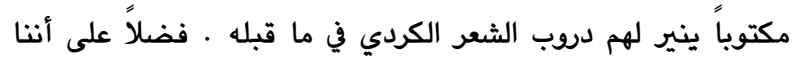
بصدد الشعر الكردي المكتوب باللهجة الكورمانجية الشمالية ، وهي أيضاً من اللهجات الكردية القديمة ، لا نملك أسماء أقدم من الشعراء

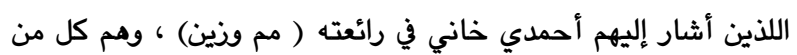
(علي الحريري ، الملا احمدالجزيري ، فقيه طيران) (4). 2.2. ثانياً: سيرة حياة الشاعر أحمدي خاني ورائعته (مم وزين) للوقوف على سيرة هذا الشاعر الكبير لابد من ذكر أهم المحطات التي مر بها، وأثرت في تكوينه الثقافي والمعري ومرجعياته الثقافية والدينية التي نهل منها معارفه وعلومه ـ تكاد تجمع المصادر التي درست سيرة هذا المبدع أنه ولد في منطقة مكاري ويالتحديد في مدينة (بايزيد) الشرقية التابعة اليوم للجمهورية التركية ، سنة (1061هـ = 1650 م) (5) . ومذا التاريخ يوافق ما ذكره الشاعر خاني في شعره في أواخر

$$
\text { ديوانه (مم وزين) (6) حيث يقول : }
$$

وهو يقلد خطوط الإثم منذ ثلاثين عاماً

$$
\text { وحين خرج من عالم الغيب }
$$

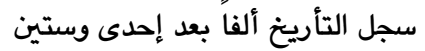

وكان له أربعا وأربعين من السنين (7).

وهنا يدون تأريخ ميلاده (1061هـ ) . ويبدوا أنه بدأ الكتابة في الرابعة منيكان عشرة من عمره ، ودون (مم وزين) وهو في الرابعة والأربعين .
ويهدف هذا البحث إلى سبر غور الأثر اللغوي في هذا المجال في شعر أحمدي خاني ، وما سلكه هذا الأثر من إثراء ثقافة الشاعر ، من خلال استخدامه الكلمات العربية والمعجم العربي في شعره ، كما يهدف هذا البحث إلى فتح أبواب جديدة لدراسة هذا الأثر في الشعر الكردي عامة ، وشعر أحمدي خاني خاصة وإلى توجيه الاهتمام إلى أثر العربية في الشعر الكردي فضلاً عن تميز الشاعر أحمدي خاني ثقافة وشعراً من الأسباب التي جعلت الباحث يلتفت لهذا البحث ، إذ إن اللذين درسوا شعر هذا الشاعر الكبير على كثرتهم ، لم تنفرد دراسة ثاقبة وكافية لهذا الجانب من شعره ، إذ نجد في مذه الدراسات إثارات عابرة أو تلميحات بسيطة ، تتناول هذا الجانب الهام من شعره ، فحاول الباحث

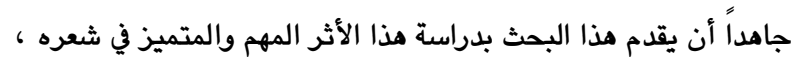
تكون لبنة من لبنات البناء النقد الأدبي عامة ونقد شعر أحمدي خاني خاصة وتفتح أفاقاً أرحب لإثراء مذا الجانب من شعر أحمدي خاني بالدراسات والبحث ، إذ أن دراسات أثر اللغة العربية في الشعر الكردي مازالت مقصرة عن الهدف المأمول . وأما الصعويات التي واجهت الباحث ، فتتمثل في قلة المصادر والمراجع التي درست أثر اللغة العربية في الشعر الكردي ، مما حدا الباحث إلى الاعتماد على ذاتيته في تحليل الأبيات الشعرية التي تحوي الكثير من الكلمات والألفاظ والشخصيات العربية الإسلامية. وقد استفاد الباحث من دراسة وترجمة (د.عزالدين مصطفى رسول ) (أحمدي خاني

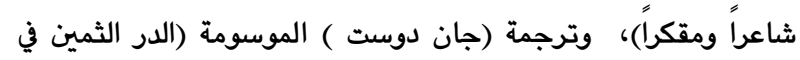

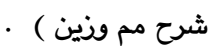

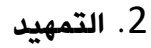

1.2. أولاً : الكرد وأدبهم

يعتبر الكرد ، بجانب العرب والترك والفرس ،إ حد ى شعوب غربي قارة أسيا اتخذ من المنطقة الجبلية الواقعة جنوب شرق تركيا وغرب إيران وشمالي العراق وشرق سوريا موطن له منذ القدم · لقد احتضنت المناطق العليا لمنابع نهري دجلة والفرات ومنذ مئات السنين ، مجموعة من القبائل أثبتت عبر القرون تجانسها الاجتماعي ووحدة لغتها وأصبحت تشكل ركائز الشعب الكردي بعد أن جرت تغييرات

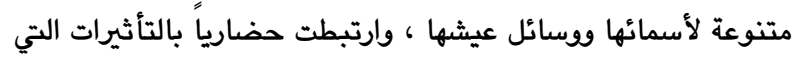
ظهرت في الحياة الدينية والثقافية لمجمل شعوب غرب أسيا ـ ولاسيما

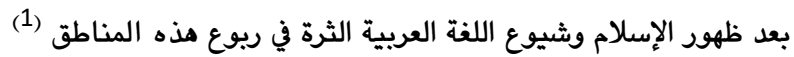
أما اللغة الكردية فهي تنتمي إلى مجموعة لغوية تشتهر بفصيلة اللغات الهندو-أوربية وهذه اللغة مستقلة لها قوانينها الصرفية والنحوية الخاصة بها ـ كما وتقسم مذه اللغة بصورة عامة إلى لهجتين الشمالية والجنوبية (الكورمانجية) . وهناك بجانب هاتين اللهجتين بعض اللهجات 
والشرعية ،والمنظومة تحتوى على ما يقارب من ألف مفردة عربية ،تدل على عناية واهتمام خاني باللغة العربية ،لقد أراد الشاعر أن تكون منظومته هذه ضمن الكتب التي يستعين بها الطلاب المبتدئون في الكتاتيب لمعرفة اللغة العربية التي تمكنهم من فهم الكتب المنهجية العربية اللسان، فقد كان الطلاب يدرسونها ويحفظونها (13) 2- منظومة (عقيدة نامه)أي رسالة العقيدة :وهى منظومة صغيرة تتألف من (73 ) بيتاً من بحر المتقارب وتتضمن العقائد الإسلامية بشكل مبسط ويصورة ميسرة واضحة ،القصد منها عرض العقيدة الإسلامية للطلبة المبتدئين من دون الخوض في المسائل الصعبة والشائكة والموضوعات التي كثر الخلاف فيها (وهذه المنظومة الشعرية

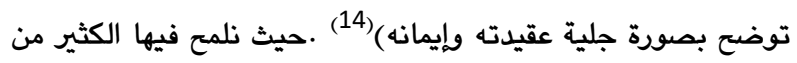
الأفكار التي يعرضها مثل الحث على التوحيد،وفكرة الخلق ،وفكرته عن الرسل الإسراء والمعراج ،الصفات الإلهية، التي أمر بها الله خلقه ،وفكرة التوبة ،ورأيه في المذاهب والخلفاء الراشدين ،وكذالك رأيه في

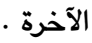

مم وزين :اختلف الباحثون والدارسون حول (مم وزين)فمنهم يسميها

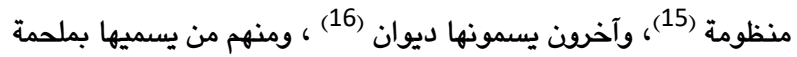
الكرد الشعرية (17) ومرة أخرى يسميها قصة أحمدي خاني الشعرية (18).ولعل أقرب وصف لـ(مم وزين)هو ديوان لأنها تتألف من حوالي (

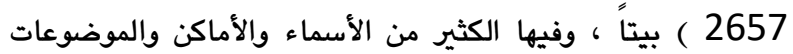
والأفكار والصور الحضارية والطبقات الاجتماعية من حكام وقواد وفيها ذكر العادات من أعراس ومأتم وعادات الصيد و الكثير من الفنون الموسيقية عند الكرد ، وفيها كم مائل من مصطلحات الصوفية

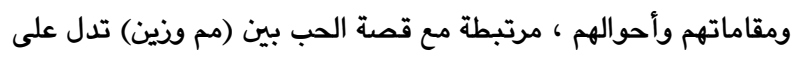

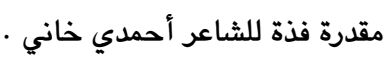

أهتم بهذا النص الخالد الكثير من الباحثين والدارسين الكرد وغيرهم . ونالت شهرة واسعة عند المثقفين وأعجب بها القراء من كل جنس لما لها فيها من الأسلوب القصصي الذي يدل على براعة وفرادة أحمدي خاني الذي صاغ بأسلويه البارع وخياله الخصب قصة من التراث الكردي وأن

كان يربطها بواقع قومه وفكرته عن الكون والإنسان والحياة . إن (مم وزين خاني إضافة إلى سمو صياغته الأدبية ، مؤلف فلسفي وفكري يلخص تجارب واضعه وأحكامه في قضايا فكرية عديدة ويعطي استنتاجات توصل إليها من خلال محاكماته العقلية لما قرأه من أفكار وأراء متباينة عبر مسار الفلسفة البشرية ، ويعطي صوراً عن حياة شعبه وعصره ) (19)، كما يبدو (خاني في مم وزين كخبير بالغناء ) (20) ونرى أن أحمدي خاني يظهر بنفسه بين أسطر (مم وزين) مفكراً وعالماً وفيلسوفاً قضى معظم عمره بين حلقات الدراسة والتدريس منكباً على الكتب ، مسامراً إياها مطلعا على كنوزها ـ ولكنه في النهاية يمثل صوتاً متميزًا متفرداً في الشعر الكردي .
ومن الباحثين اللذين أسهبوا في شرح حياة أحمدي خاني (علاء الدين سجادي) الذي أكد على أن الشاعر عاش في بايزيد و أورفة واخلاط وتبليس (8) . مستنداً في ذلك على التحليل والاستفسار الدقيق المتواصل حول الشاعر عند المهتمين بأدبه وتراثه في كردستان الشمالية . ويرى الدكتور( عز الدين مصطفى رسول ) إن الأقرب والصواب لمعرفة حياة هذا الشاعر هو الرجوع إلى نصوص (مم وزين) التي فيها من الإثـارات الواضحة التي تصف جغرافية المنطقة التي ارتبط خاني بها وهذه الصلة تدل على أنه عاش فيها (9) . درس الشاعر في المساجد وتلقى علوم الدين والمعرفة على يد شيوخ زمانه ، وكذلك درس في المدارس المنتشرة في المدن الكبيرة في (تبريز

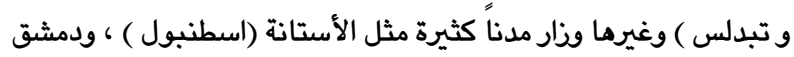

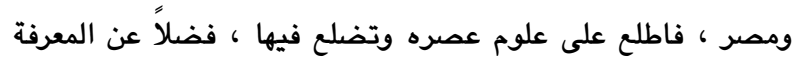

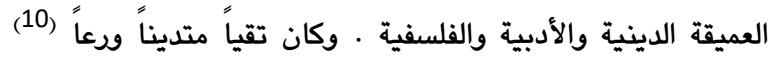
اشتغل الشاعر بالإمامة والتدريس في مدينة ( بايزيد ) وعاش حياة زاخرة بالعلم ومجالسة العلماء ، كما واشتغل ككاتب في ديوان الإنشاء عند

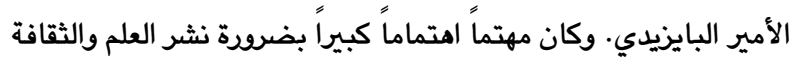
بين أفراد قومه لذا قام ببناء مسجد خاص به بظاهر البلدة ، وألحق بها مدرسة تعنى باستقبال طلاب العلوم الشرعية وتهيئهم وتثقيفهم (11) وهذه المكانة التي نالها الشاعر كانت بفضل ثقافتهاله الواسعة

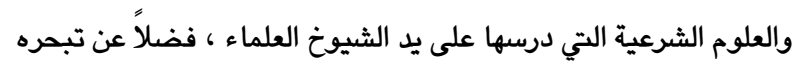
باللغات العربية والتركية والفارسية ويالأخص العربية ـ التي نهل من ينبوعها الثر المعارف التي استطاع بهذه المعرفة الواسعة باللغة العربية أن يفهم الدين الإسلامي الفهم الصحيح ، كما نال الإجازة العلمية وأصبح

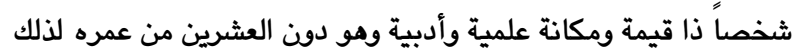
تم اختياره ككاتب في الديوان الأميري (12) ترك الشاعر أحمدي خاني مؤلفات عديدة منها : 1- نو بهارا بجوكان أي (الربيع الجديد للصغار)في (37) صفحة من القياس الصغير مكتوب بالأحرف العربية طبع مرات عديدة من أهمها الطبعة الثانية في دمشق(1956 م ). (الملا محمد رمضان البوطي ) وهو عبارة عن قاموس عربي _ كردى بسيط في بدايته ،ثم يبحث في صفحات منه عن أهم المبادئ والأسس التي يجب أن يتعلمها الطلبة الصغار من الأمور الشرعية الدينية.وفيه إثـارات وتعريف بعروض الشعر العربي وهذا القاموس يدل على حب و اهتمام أحمدي خاني للغة العربية وأراد بهذا العمل نشر المعارف الإسلامية باللغة العربية حتى يتسنى للطلبة الصغار من الكرد التعود على اللسان العربي الفصيح الصحيح ومن خلاله يعرف الإسلام والقرآن الكريم .وهى منى منظومة شعرية تتألف من ( 216 ) بيتاً،وتنقسم على ( 13 ) فضلاً مع مقدمة نثرية قصيرة ،وهى تبحث في ترجمة مجموعة من المفردات العربية إلى الكردية التي يحتاج إليها الأطفال الكرد الذين يتوجهون لترجيه صوب المساجد والمدارس الدينية ليتزودوا بالمعارف والعلوم اللغوية 
يا واجدا بغير نظير ولا ثبيه

يا خالق الإنس والجان جميعا (26)

قد أنشأها جملة تباركت الملك والملك والفلك

سبحان كما خلقت أحسنت فكيف ما فلقت

كفاك أيها الحبيب المختار

أن يقسم بك الباري نفسه

أيها الباري اجعل من سيء الفعال

ثبيه الكلاب هذا تابعا للأصحاب (27) منيه ليهاء

وقوله : - و

امنن بالله علينا أيها الساقي

واسكب جرعة من الخمر في كأس جم

فلو كان لنا ملك

يراه الله جديراً بتاج ما مان ملان

ويعين له عرش ما لابتسم لنا الحظ وأشرق (28)

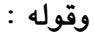

وقاكم الله منها يا جموع الشباب

فهي ومضة في سورة الفاتنات

أحسني بالله عالجيهما واعدي دواء لما بهما

قالتا بالله يا ثابتة الجنان

أسحرت هذين الملكين

ماذا قال رملك مل عرفت الحوريين (29)

نقش اختاره الله

من القادر على تغييره

ألا ترى سلطان العرش الذي لا طمع عنده

لقد خلق لتحقيق هذه الإرادة

عددا من السلاطين

وزاد عليهم أضعافهم من الشياطين(30)

الأعلام والأسماء: وردت أسماء الأنبياء و الأعلام المشهورة المعروفة

في اللغة العربية في (مم وزين) منها :

يقول :

جعلت ليلى بلاءً لقيس

يوسف أظهرته سراجاً إمام زليخا

جعلت من ادم قبلة و مسجوداً له

وكذلك أبلغت عيسى الأوج

ولقنت إدريس درساً خفيا
3. المبحث الأول : المفردات والأسماء العربية (21)

إن الباحث في (مم وزين) يجد أنها تزخر ويشكل ملفت للنظر ، بكلمات من اللغة العربية سواء كانت هذه الكلمات قد ذكرها الشاعر أحمدي

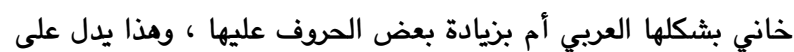
اطلاع أحمدي خاني على اللغة العربية دراسة وفهما وحبا وارتباطا لمعرفة الإسلام والقرآن ، لأن اللغة العربية مستودع الأمة الإسلامية ، وجامعة شمل المسلمين وموحدة كلمتهم فكانت عناية الشاعر خاني بها كبيرة ومتنوعة وواسعة ـ ظهرت هذه العناية من خلال الأبيات الشعرية الكثيرة والمتنوعة في (مم وزين) التي تحوي الألفاظ العربية ، التي لا تخلو من أي بيت من أبياتها بل لعلنا لا نغالي أذا قلنا إن الشاعر ورين أحمدي خاني كان له القدح المعلى في حبه العربية والثقافة الإسلامية ، بل ولقد (سخر قدراته الذهنية والكتابية للدعوة إلى الشريعة المحمدية وتكريس اللغة العربية ، باعتبارها لغة الدين وربط الأكراد ، صغاراً كباراً بنهج الإسلام ) (22) . فهذا النص الإبداعي تحقق على أرضية اللغة باعبارها العربية وفي فضاء من الثقافة الإسلامية وحضارتها العريقة بل يعد إبداع يصب في خانة الأدب العربي فالصور و التشبيهات والاستعارات وسائر المحسنات اللغوية والابتكارات البديعية من جناس وطباق ومترادفات وتضادات إنما هي من أصول اللغة العربية ـ وفيها من أثر اللغة العربية الكثير. ( لقد شيد أحمدي خاني البنيان اللغوي في (مم وزين) ، من أساسه وفقاً للمنظور الأدبي والبلاغي واللغوي القائم في اللغة العربية ،

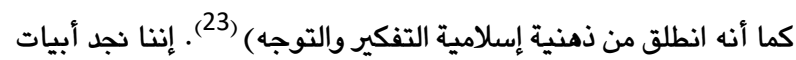
شعرية في (مم وزين) عربية بالكامل وأخرى في معظم ألفاظها ، ونذكر منا نماذج وعينات هذه الألفاظ ، قد اخترناها لأنه من غير الممكن أن ونان

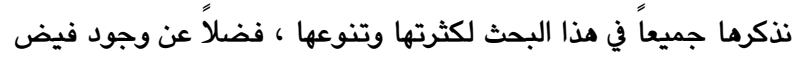
زاخر من المفردات التي استطاع الشاعر أحمدي خاني أن يوظفها في هذا النص المتميز بشكل أو بأخر سواء كانت هذه المفردات ذات

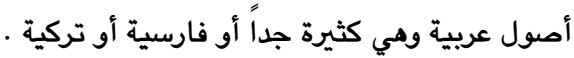
لفظ الجلالة (الله): وردت في (مم وزين) في أول بيت منها :

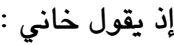

$$
\text { فهي ناقصة بغير أسمك والله (24) }
$$

وكذلك يقول :

إنما الروح والجسد قد نوجا

جبرا وقضاءً بأمر الله وصفوة القول إننا لم نر

أحداً عارفاً بحكمتك تبارك الله (25)

وقد وردت ألفاظ خاصة بالله تعالى من أسماء وصفات بشكل كبير في النص الشعري (مم وزين) منها على سبيل المثال لا الحصر . قوله : يا واحداً بغير شريك ويغير صنو 


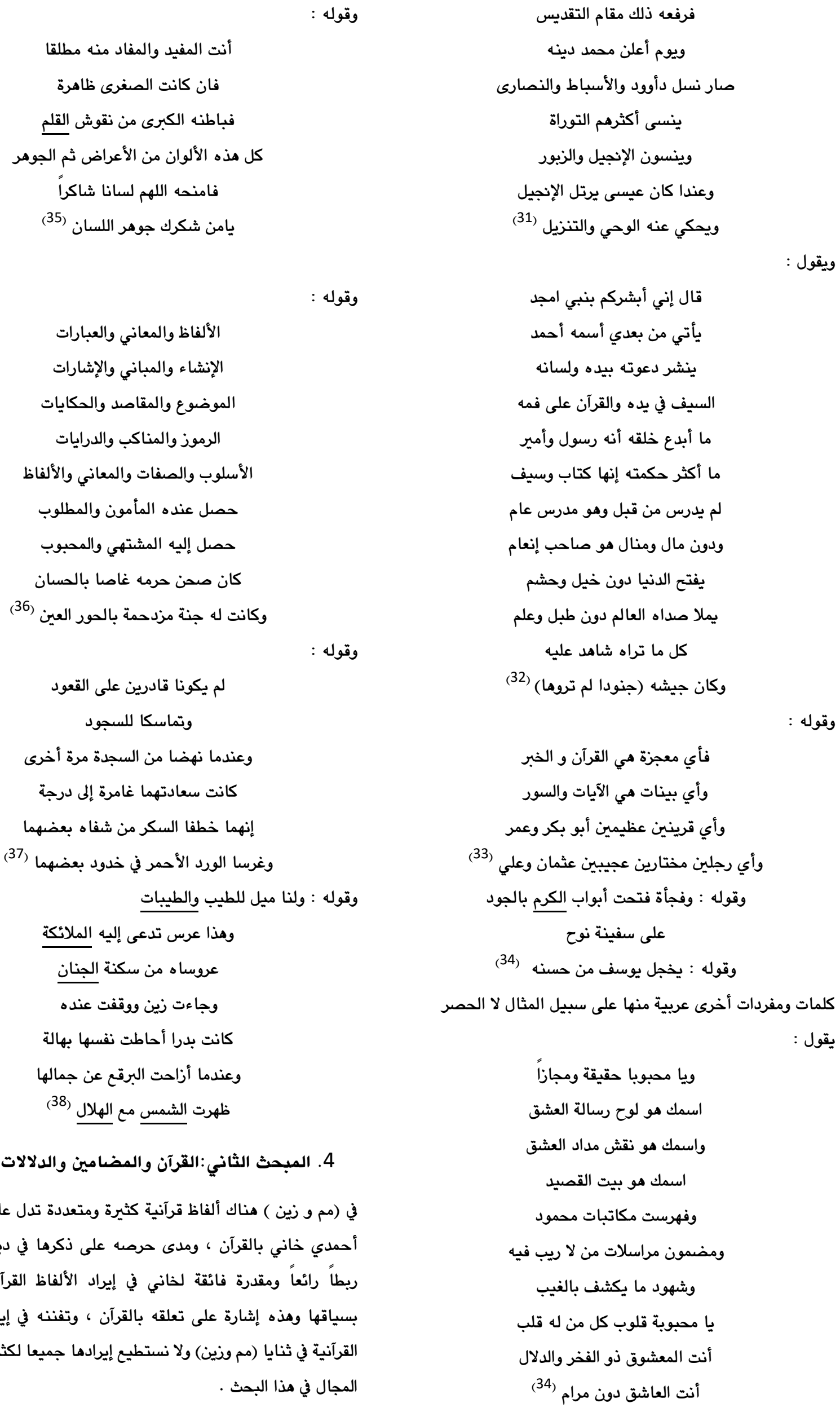




$$
\begin{aligned}
& \text { عندما شرب مم وزين الخمرة } \\
& \text { نطق مني موضع الجرح } \\
& \text { فنحن العشاق وان كنا غواني خمر } \\
& \text { إلا أننا سكارى بخمرة ألست (44) }
\end{aligned}
$$

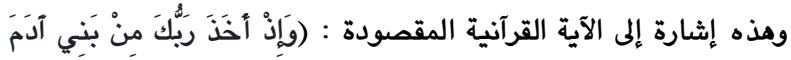

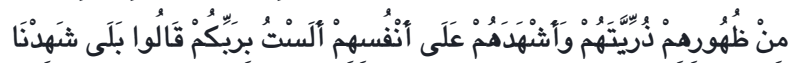

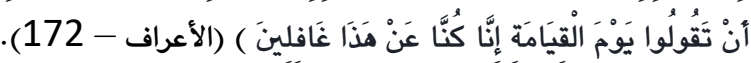
وقوله :

$$
\begin{gathered}
\text { اقترضت هذه الرقح من بائع الأرواح } \\
\text { وإذ قال اقلعي ظاهرا }
\end{gathered}
$$

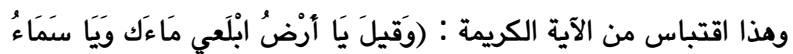

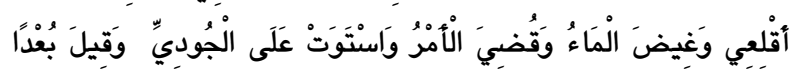

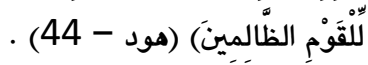

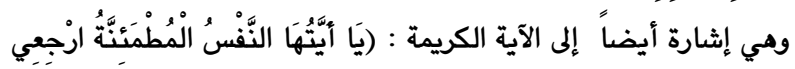

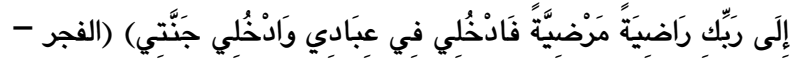

ومكذا وجدنا أن في مم وزين صورا وإشارات قرآنية ولوحات كثيرة ،

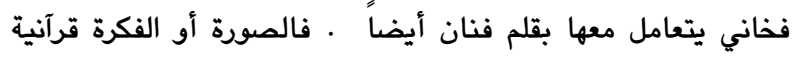

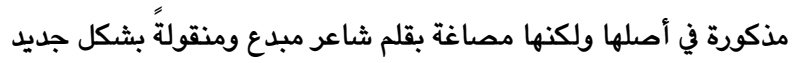
ومع إضافات جديدة . إننا نجد صياغة جديدة للصورة القرآنية في مم وزين . ومي إفات إن مفردات الصورة القرآنية تعود إلى صورة خاني منفردة أيضاً ، ولكن كل واحدة منها تقابل مفردة في قصة العشق وفي عناصر الحب المكونة لقصة العشق · كقوله :

العشق نار والجسد جبل طور

والقلب هو تلك الشجرة التي تشتعل ناراً ونوراً

$$
\text { والقفص مشكاة والقبس سراج }
$$

إن صورة موسى الأثيرة لدى المتصوفة وسيلة لإيجاد صور أدبية

$$
\begin{aligned}
& \text { أخرى عديدة عند خاني مثل قوله : } \\
& \text { أرأيت كيف أدى تاجدين الأمر } \\
& \text { إنه موسى قد شق أمامنا بحر الهموم (47) }
\end{aligned}
$$

(إن تعامل خاني مع مذه الآية هو نفس تعامله مع آيات وصور قرآنية

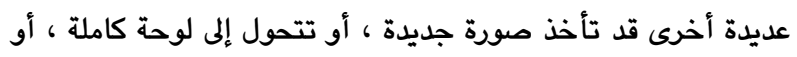

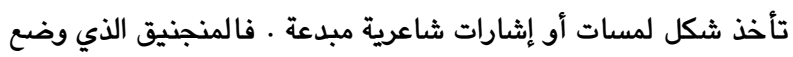

فيه إبراهيم الخليل ولم يحرقه يهدي خاني إلى صورة معاكسة). (48)

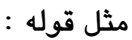

$$
\begin{aligned}
& \text { يفتح الدنيا دون خيل وحشم } \\
& \text { يملا صداه دون طبل وعلم } \\
& \text { كل ما تراه شاهد عليه } \\
& \text { وكان جيشه جنودا لم تروها (39) }
\end{aligned}
$$

في هذه الأبيات إشارات واضحة إلى ما يروى من الكرامات إلى ما في الآية

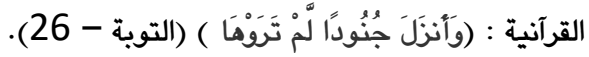
وقوله :

أيها الباري اجعل من سئ الفعال

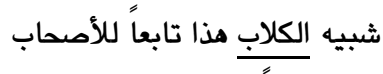

يا لائقا بقرب قاب قوسين

يا ملك ملوك مكة والمدينة ما أكثر ما رينا منك من معجزات تحريك الأفلاك عندك لحظة من الزمن

$$
\text { فعليك السلام يا فخر الملائكة }
$$

$$
\text { و زاغ البصر عندك عبارة (40) }
$$

وهنا إثارة إلى قصة أصحاب الكهف وقاب قوسين وشق القمر وذاغ البصر وهذه دلاله واضحة على وجود التناص القرآني في ثقافة الشاعر أحمدي خاني وتمكنه من ربط السياق الشعري بالآيات القرآنية .

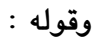

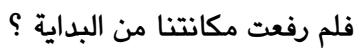
وضغت على رؤوسنا تاج التكريم

$$
\text { ومنحتنا شرف الخلافة }
$$$$
\text { عندما أودعتنا أمانتك (41) }
$$

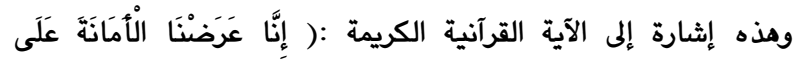

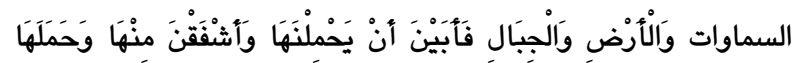

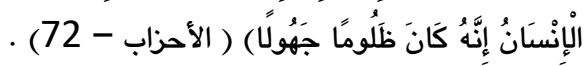
وليقولوا : ها قد دون تدوينا ماهراً

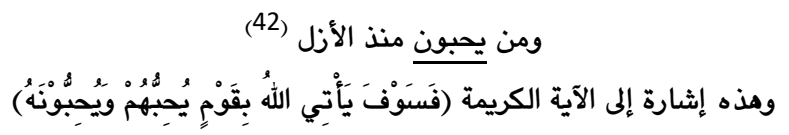

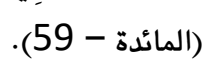

وقوله :

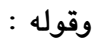$$
\text { كل روضة هي مثابة الخلد الأكبر }
$$$$
\text { كل نبع هو من عين ماء الكوثر }
$$

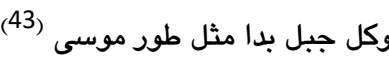

أي شجرة جبل الطود وتقول الأية القرآنية الكريمة : (إِنَّنِي أَنَا اللَّهُ لَال

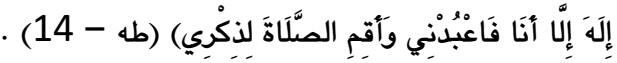


ما أبدع خلقه أنه رسول وأمير

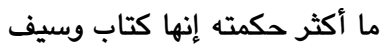

لا خيمة ولا موكب ولا إيوان

كانت السحب له ضلالا

بقدر ما كان من قبل عليما (50).

إثارة إلى الحديث النبوي (علماء أمتي كأنبياء بني إسرائيل) .

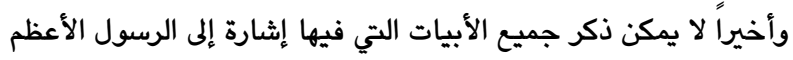

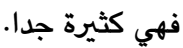

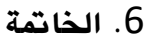

بعد هذه الوقفة مع النص الخالد ( مم وزين ) يمكن أن نستنتج منه ما

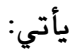

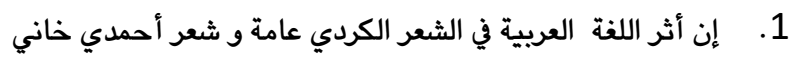
خاصة كان واضحاً وكبيراً ومتميزاً ، وأن شعراء الكرد قد نهلوا من هذه أنه

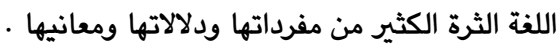
2. وجدنا أن أحمدي خاني بثقافته ومرجعيته الدينية الإسلامية ومعرفته باللغة العربية استثمر و وظف هذه المريكا وزين)بشكل جيد. 3. وجدنا في (مم وزين) الكثير من الألفاظ ، والمفردات العربية التي

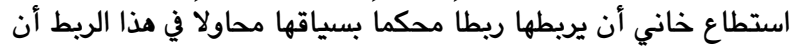
يشيع الألفاظ والمفردات والمعاني العربية بين قومه .

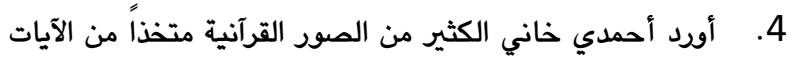
القرآنية مرجعاً ومنطلقا في سبيل الرجوع إلى النص القرآني واثبات

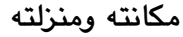
5. إن خاني في (مم وزين) ينطلق من أفكاره التي يؤمن بها ويدعو إليها. 6. لقد استطاع الشاعر أحمدي خاني في ( مم وزين ) أن يثبت

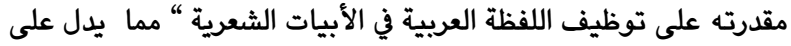
أن المعجم العربي كان من أهم مرجعيات الشاعر الثقافية .

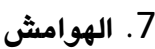

1- ينظر : الكتب التي تتحث عن الكرد تاريخهم كثيرة جدا نذكر منها تاريخ

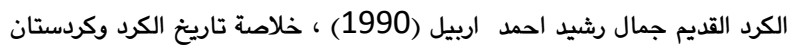

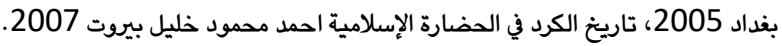

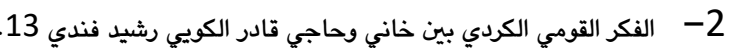
3- - ينظر : لمصدر نفسه 13. 4- - - المصدر نفسه 13. 5- تاريخ الأدب الكردي علاء الدين سجادي ـ 148

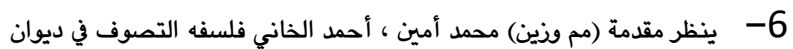

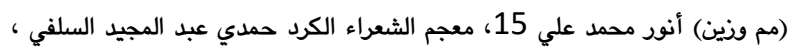

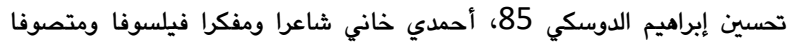
الدكتور عزالدين مصطفى رسول 27.
فبطله يعيش بين الورود ، ولكن مرابع الورد ليست سوى المنجنيق بالنسبة للعاشق الولهان فهو يقول :

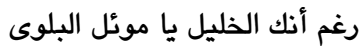
فبستان الورود يغدو لك ناراً (49)

ويمكن القول : إن مثل مذه الصور القرآنية اعتمدها كثيرا خاني في (مم وزين) وهي عنده تأخذ مجالات كثيرة ، ومتنوعة بل إن التشبيه والصورة القرآنية تتوسع في بعض الأحيان لتأتي بشكل لوحة قرآنية

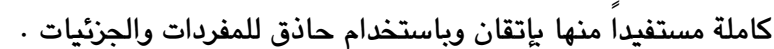

5. المبحث الثالث : الرسول (صلى الله عليه وسلم) في (مم

\section{وزين)}

إن شخصيات الأنبياء (عليهم السلام) هي أكثر شخصيات التراث

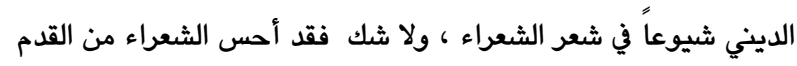
بأن ثم روابط وثيقة تربط بين تجربتهم وتجربة الأنبياء ، فكل من النبي والشاعر الأصيل يحمل رسالة إلى أمته ، والفارق بينهما أن رسالة النبي رسالة سماوية ، وكل منهما يتحمل العناء والعذاب في أداء رسالته

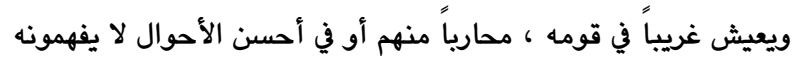
ـ وأكثر شخصيات الرسل شيوعاً شخصية محمد (صلى الله عليه وسلم)

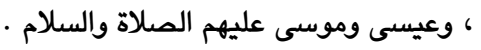
إن النبي محمد (صلى الله عليه وسلم) ما يزال الأنموذج المثالي الذي تهفو إليه القلوب المؤمنة ، وتتعطر بسيرته الألسنة الذاكرة ، فهو المثل

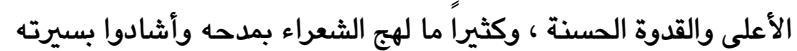

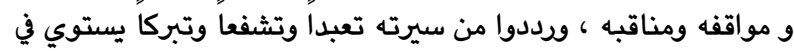
ذالك شعراء الصوفية وغيرهم ، ولم يكن أحمدي خاني إلا واحدا من الشعراء الذين تغنوا بسيرة الرسول محمد (صلى الله عليه وسلم) فمدحه في (مم وزين) بطريقة صوفية أدبية تدل على ما يكن للرسول الأعظم من حب وتقدير فنجد إن خاني قد مدح الرسول محمد (صلى الله عليه وسلم) بأبيات كثيرة منها قوله:

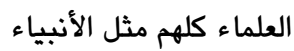
والعابدون كلهم أولياء معا فأي معجزة هي القرآن والخبر وأي بيّنات هي الآيات والصور

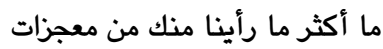
فعليك السلام يا فخر الملائكة وعندما كان عيسى يرتل الإنجيل ويحكي عنه الوحي والتنزيل قل إني أبشركم بنبي أمجد

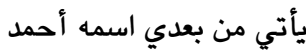
ينشر دعوته بيده ولسانه السيف في يده والقرآن على فمه لئه 


$$
\begin{aligned}
& \text { 34- المصدر نفسه } 153 \text {. } \\
& \text { 35- المصدر نفسه } 181 \text {. } 153 \\
& \text { 36- المصدر نفسه } 192 \text {. } 185 \\
& \text { 37- المصدر نفسه } 198 \text {. } 198 \\
& \text { 38- المصدر نفسه } 198 \text {. } 198 \\
& \text { 39- المصدر نفسه } 348 \text {. } 348 \\
& \text { 40- المصدر نفسه } 29 \text { - } 30 \\
& \text { 41- المصدر نفسه } 32 \text {. } 32 \\
& \text { 42- المصدر نفسه } 37 \text { - } 38 \text {. } 38 \text {. } \\
& \text { 43- المصدر نفسه } 40 \text { - } 41 \text {. } 4 \\
& \text { 44- المصدر نفسه } 156 \text {. } 150 \\
& \text { 45- المصدر نفسه } 263 \text {. } 26 \text {. } \\
& \text { 46- المصدر نفسه } 23 \text {. } 25 \\
& \text { 47- المصدر نفسه } 25 \text {. } 28
\end{aligned}
$$

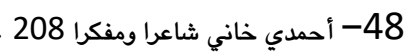

$$
\begin{aligned}
& \text { 49- مم وزين } 43 \text {. } 40 \text {. } \\
& \text { 50- المصدر نفسه } 47 \text {. } 47
\end{aligned}
$$

\section{8. - المصادر والمراجع}

1- أحمد الخاني فلسفة التصوف في ديوانه مم وزين ، أنور محمد علي ط 1 دار

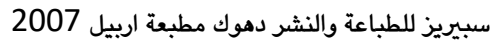

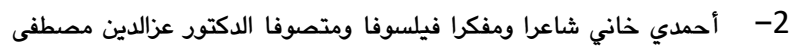

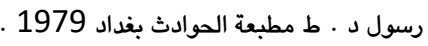

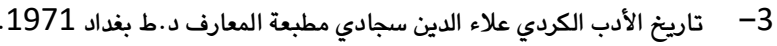

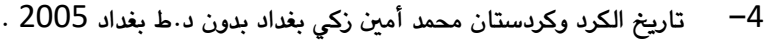

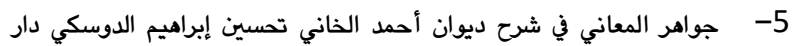

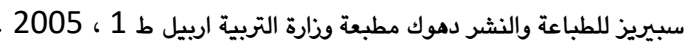

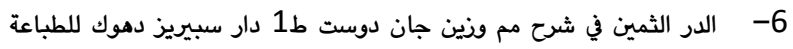
والنشر اربيل 2006 . 7- الفكر القومي الكردي بين خاني وحاجي قادر الكويي دراسة نقدية رشيد فندي ط 1 دار سبيريز دهوك كردستان العراق 2008 ـ 2008

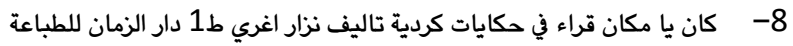
والنشر والتوزيع دمشق - سوريا 2006 ـ 200 9 - معجم الشعراء الكرد إعداد حمدي عبدالمجيد السلفي وتحسين ابراهيم الدوسكي دار سبيريز ط1 دهوك للطباعة والنشر اربيل 2008 دمبردي

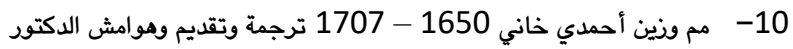
عزالدين مصطفى رسول د.ط السليمانية مطبعة قه شنك 2000 11- مم وزين محمد أمين بوز ارسلان د.ط استنبول 1998 د. 19

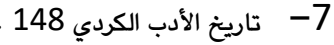

$$
\begin{aligned}
& \text { 8- ينظر: أحمدي خاني شاعرا ومفكرا } \\
& \text { 9- ينظر : أحمدي خاني فلسفة التصوف } 16 \text { - } 10 \\
& \text { 11- ينظر : المصدر نفسه 24-25. } \\
& \text { 12- ينظر : المصدر نفسه 24-12 :-12 }
\end{aligned}
$$

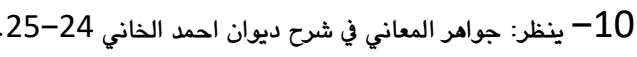

13- لعل أول من نشرها ضياء الدين المقدسي ضمن كتابه (الهدية الحميدية في

اللغة الكردية) المطبوع سنة 1310هـ =1892 في استانبول وكذلك نشرها الملا

محمد رمضان طبعة الثانية في دمشق سن 1956 . 195

14- أحمد الخاني فلسفة التصوف 23 .

15- ينظر: المصدرنفسه 24_33حيث فصل الباحث انورمحمد علي هذه

المسائل ذاكرا الابيات الشعرية.

16- ينظر : معجم الشعراء الكرد 108 ، وجواهر المعاني 32 ، وكان يا مكان

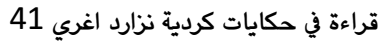

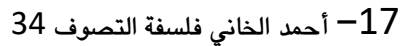

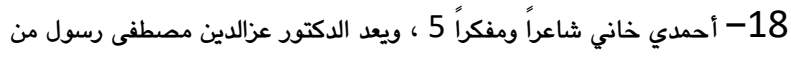

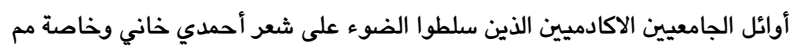

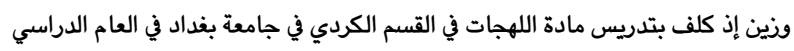
(1967-1966)

19- مقدمة مم وزين ترجمة وتقديم وهوامش الدكتور عز الدين مصطفى رسول 4 ولقد اعتمدنا في هذا البحث على هذه الترجمة التي هي اقرب إلى النص الأصلي ففيها ذكر الدكتور مصطفى من الهوامش الكثير .

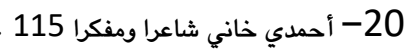
21- اعتمدنا في هذا البحث على ترجمة الدكتور عزالدين مصطفى اذ كتب الابيات

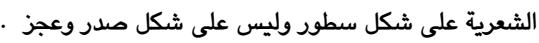

22- كان يا مكان قراءة في حكايات كردية 84 .

$$
\begin{aligned}
& \text { 23- المصدر نفسه } 86 \\
& \text { 24- مم وزين } 23 \text {. } \\
& \text { 25- المصدر نفسه } 25 \\
& \text { 26- المصدر نفسه } 27 \\
& \text { 27- المصدر نفسه } 33 \\
& \text { 28- المصدر نفسه } 41 \\
& \text { 29- المصدر نفسه } 42 \\
& \text { 30- المصدر نفسه } 47 \\
& \text { 31- المصدر نفسه } 47
\end{aligned}
$$$$
\text { 32- المصدر نفسه } 128 \text { - } 129 \text {. }
$$$$
\text { 33- المصدر نفسه } 134 \text { - } 135
$$ 


\title{
كاريگهريا زمانىٌ عهرهبى لسهر هوَزانا كوردى (ديوانا مهم و زينا خانى وهك نموونه)
}

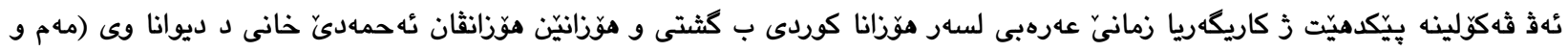

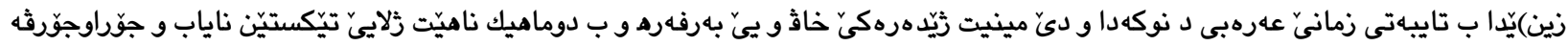

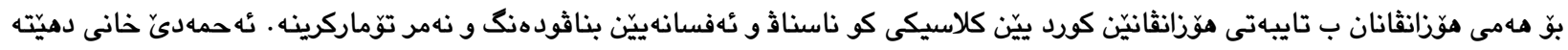

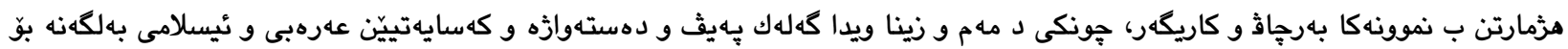

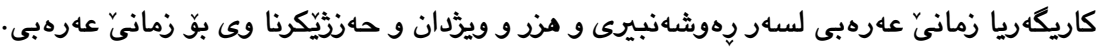

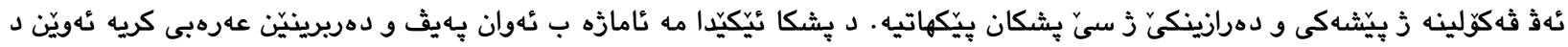

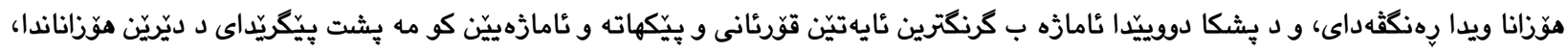

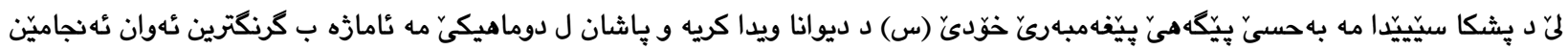
كو ئهم كه هشتينى كريه.

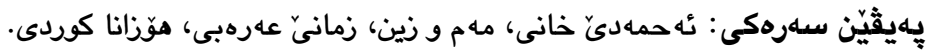

\section{INFLUENCE OF ARABIC LANGUAGE ON KURDISH POETRY: POEMS OF AHAMADIKAHINE " MAM ZEIN" AS AN EXAMPLE.}

\begin{abstract}
The present research deals with the Influence of Arabic language on Kurdish poetry: Poems of Ahamadi Kahines collection named " Mam Zein " Due to the richness and diversity of texts of Arabic poems, Arabic language is always regarded as and still a rich and non - depleted resource for all poets, especially Kurdish poets who took lines of immortality and glory.

The poet Ahamadi Kahine is an example for this Influence as this collection " Mam Zein " contain a lot of Arabic and Islamic utterances, vocabularies, meanings, and figures that shows to what extent how Arabic language has Influenced his education, his emotion, and his love for Arabic language.

The present research is divided into introduction and three chapters. In the first chapter, we explained Arabic vocabularies and names, while in second one we explained Quran, Qurainc meaning and contents. In third chapter, we explained the prophet in " Mam Zein ". The research has come up with many finding and conclusions.
\end{abstract}

Keywords: Ahamadi Kahines, Mam Zein, Arabic Language, Kurdish poetry. 